The building is approached by way of University Walk, with the gardens of the Royal Fort on the left and the Baptist College on the right. The main entrance leads directly to a spacious entrance foyer, in which will be noticed a plaque recording the special connexion between the Society of Merchant Venturers and the Faculty of Engineering. Like the walls around the entrance foyer, it is of gris mouchette, a marble-like limestone from northern France. The exterior is faced with a light-coloured brick from Cheshire with the principal features in Bath stone. Of the three main floors in the building, the lower ground floor is devoted to engineering laboratories: mechanical engineering in the wost wing, aeronautical engineering in the east wing and civil engineering in the centre, with an additional laboratory under the Library. The ground floor, on the level of the main entrance, houses electrical engineering in the west wing and part of the centre, and the Department of Geology in the east wing. From the lower floors there is access to the Library which, with its gallery above, and stack room below, houses some 10,000 volumes and is designed to accommodate many more. On the first floor, lecture theatres and staff rooms occupy the centre block, with drawing offices, lecture rooms and tutorial rooms in the wings. At this level, also, the Departments of Mathematics and of Theoretical Mechanics are housed; the former, which serves the University as a whole, occupies much of the lecture room accom modation in the east wing, and the latter, which works primarily with the engineering departments, uses rooms in the west wing.

Further staff rooms are provided in a second floor which extends along the middle part of the building. Here also are some of the rooms set apart for postgraduate students.
It will be seen that the building gives all the departments within it new opportunities for extending or improving their equipment for both teaching and research purposes. In the field of civil engineering, the range of apparatus for the strength-testing of structures has been extended, and provision made for dynamic as well as static testing; and facilities for work on hydraulies and soil mechanics have been much improved. Better workshops, extended facilities for material and fatigue testing, and provision for the testing of gas turbines have become possible in the new mechanical engineering laboratories. The electrical engineering laboratories, in addition to extended testing equipment for general purposes, now provide several specially designed generator sets, which are the basic tools needed for research into problems in dynamo-electric machinery. The Department of Aeronautical En. gineering, which owes much to the generosity of the Bristol Aeroplane Company in founding the Sir George White chair of aeronautical engineering some years ago, has several low-speed wind tunnels in operation, and more are planned. Compressors and a large high-pressure air reservoir are installed to provide for the operation of transonic and supersonic wind-tunnels. The Department of Geology has now adequate space for the display of its extensive collection of geological specimens, and has extended its laboratory work generally. All the Departments have been able, in addition to their teaching laboratories, to set aside proper space for research work.

There is no doubt that the provision of Queen's Building should enable Bristol to make an even greater contribution than it has in the past to the highly important field of technology and applied. science.

J. F. BAKER

\title{
OBITUARIES
}

Prof. E. J. Maskell, F.R.S.

By the death of Ernest John Maskell on December 20 plant physiology in Britain has lost one of its most distinguished exponents.

Born in Cambridge on February 1, 1895, Maskell was educated at Cambridge County High School and the University of Cambridge, where he was a member of Emmanuel College. He graduated in 1919. With the award of the Frank Smart Studentship in 1920 he undertook research in plant physiology under the late F. F. Blackman. The results of this work on the diurnal rhythm of photosynthesis in leaves of cherry laurel in relation to carbon dioxide concentration, and on rates of photosynthesis in relation to stomatal opening, were afterwards published in the Proceedings of the Royal Society. After an appointment in 1922 to the Horticultural Research Station at Cambridge and a period at Rothamsted Experimental Station (1924-26), Maskell was appointed as plant physiologist at the Cotton Research Station in Trinidad. It was here, during 1926-30, that in conjunction with T. G. Mason he carried out the work by which he is best known and by which he is likely to be chiefly remembered, on translocation of carbohydrates, nitrogenous substances and phosphorus, potassium and calcium compounds in the cotton plant.

By 1930 Maskell's outstanding quality as an experimental plant physiologist was well realized and he was recalled to Cambridge to take up a lectureship, which was later raised to the post of reader in plant physiology. Here in the Cambridge Botany School for twenty-one years he was an inspiration to the many research students from Britain and overseas who had the advantage of his direction and supervision.

In 1951 Maskell was appointed to succeed me in the Mason chair of botany in the University of Birmingham. Just before his death he had been engaged in the troublesome task of developing plans for a new Botanical Department of the University.

Maskell was elected a Fellow of the Royal Society in 1939 and served on the Council of the Society during 1951-53. He was a member of the Agricultural Research Council during 1952-57 and represented the University of Birmingham on the governing body of Studley College from 1951 until his death. He was also a member of the governing body of the Grassland Research Institute, Hurley, a member of the executive committee of East Malling Research Station, of the Scientific Advisory Committee of the Empire Cotton Growing Corporation, and of the Advisory Panel of the Indian Tea Research Association.

Maskell was a life-long and active member of the Society of Friends and during the First World War served with a Friends Ambulance Unit. He was the most upright and kindest of men and those who had the privilege of his friendship held him in the highest 
regard. He married in 1923 Elisabeth Rose McCormick, who survives him. WALTER StiLES

\section{Prof. N. J. Scorgie}

Prof. N. J. Scorgie, Courtauld professor of animal husbandry in the Royal Veterinary College, London, died suddenly in his fiftieth year on February 10, 1958, in Iran, where at the instigation of the Food and Agriculture Organization of the United Nations he was conducting a mission related to re-organization and development of animal husbandry services. Jack Scorgie, as he was commonly known, was a 1929 arts and 1931 science graduate of Aberdeen, after which he took his veterinary diploma at the Royal
Veterinary College and then joined the staff of that Institute. Following preliminary work in the Pathology Department and in preventive medicine, he transferred to the Department of Animal Husbandry, where he worked under Prof. W. C. Miller, whom he succeeded in 1946.

Scorgie had made the most of his wide training and was beginning to reap the benefit of his labours in organizing his Department, partly in new quarters, at the time of his death. He will be remembered best for his work on trichomoniasis in cattle, housing problems and poultry husbandry, being with the late Dr. Black, of Reading, the first to report on the successful applications of artificial insemination in fowls (Gallus domesticus).

\section{NEWS and VIEWS}

Plant Physiology at the Imperial College of Science and Technology : Prof. Helen K. Porter, F.R.S.

Dr. Helen K. Porter, who has recently been appointed to the chair of plant physiology in the Imperial College of Science and Technology, London, is the first woman to hold a chair in the College. After graduating from Bedford College, London, in 1921, she spent a year in the Department of Organic Chemistry at the Imperial College, and was then appointed research assistant in the Department of Botany. Ten years later she joined the staff of the Research Institute of Plant Physiology attached to the Imperial College, and concentrated primarily on research in the field of carbohydrate metabolism. Shortly after the Second World War she spent a year in Washington University, St. Louis, studying enzymological methods. The subsequent development of her work, in collaboration with a group of colleagues and postgraduate research students with the support of the Nuffield Foundation, led to the opening in 1953 of an enzymology laboratory in the Institute of Plant Physiology, to accommodate a research group under Dr. Porter's direction. In 1956 she was elected to Fellowship of the Royal Society. In 1957 Dr. Porter was appointed to a new readership in enzymology at the Imperial College.

Burden Neurological Institute : Prof. F. L. Golla Prof. F. L. Golla, director of the Burden Neurological Institute, Bristol, since 1939, is to retire. Prof. Golla, who followed Sir Frederick Mott as director of the Central Pathological Laboratory at the Maudsley Hospital, London, has for many years been a leading figure in nouropsychiatric research. Primarily a physiologist by training, his interests have extended into endocrinology, biochemistry, pharmacology and psychology, while his medicine has been constantly refreshed by gleanings in the German, French and Italian literature. His erudition. is immense. In 1939 Prof. Golla moved to Bristol to start the Burden Neurological Institute, which, under his direction, has become widely known throughout the world.

Of Prof. Golla's research achievements, one of the most remarkable was his early application of the electroencephalograph to the study of neurological and psychiatric disorders, and, ably assisted by Dr. Grey Walter, he established the diagnostic value of the technique in cases of cerebral tumour and other lesions of the brain. He was also a pioneer in attempting the surgical treatment of epilepsy by the removal of epileptogenic foci, and played an important part in the development of electro-convulsive therapy. Many generations of students at the Maudsley Hospital remember with gratitude the inspiration of his lectures on the physiology of the nervous system. He has a style of his own and combines a keen critical capacity with a breadth of vision that is unique. In 1950 there appeared a volume entitled "Perspectives in Neuropsychiatry", which was published by old pupils and colleagues as a present for Prof. Golla's seventieth birthday. Always full of new ideas, he has found his pleasure and inspiration in his work and cares little for publicity or personal rowards.

Dr. W. Ross Ashby

Dr. W. Ross Ashry, who now succeeds Prof. Golla, was previously director of the Research Laboratory at Barnwood House, Gloucester. $\mathrm{He}$ was educated at Cambridge and St. Bartholomew's Hospital and was at one time engaged as a pathologist at the Watford Peace Memorial Hospital and as a house physician at Bethlem. $\mathrm{He}$ is probably best known for his work on the 'homeostat', an electronic device designed to parallel the homeostatic mechanisms of the brain. His interest in the behaviour of neuronal nets led to the writing of the book, "Design for a Brain", which is very widely known.

\section{Bell Telephone Laboratories Appointments :}

Dr. James B. Fisk

Dr. JAMES B. Fisk, executive vice-president of the Bell Telephone Laboratories, has been elected president as from January 1. Dr. Fisk succeeds Dr. Mervin J. Kelly, who has been elected chairman of the board of directors. Dr. Kelly has served as president of the Laboratories since 1951. Mr. Estill I. Green, vice-president in charge of systems engineering, is to be executive vice-president as from January 1.

Dr. Fisk, who has been associated with the Bell Laboratories for nearly twenty years, has combined a distinguished career in industrial research with outstanding service to the Government in the field of science. He was director of the Division of Research of the Atomic Energy Commission in 